\title{
Linx
}

Revue des linguistes de l'université Paris X Nanterre

$54 \mid 2006$

La cause : approche pluridisciplinaire

\section{Les universaux empiriques du langage : tremplin pour l'étude d'autres universaux humains et outil dans l'exploration de différences transculturelles}

\section{Anna Wierzbicka}

Traducteur : Bert Peeters

(2) OpenEdition

Journals

Édition électronique

URL : http://journals.openedition.org/linx/517

DOI : $10.4000 /$ linx. 517

ISSN : 2118-9692

Éditeur

Presses universitaires de Paris Nanterre

Édition imprimée

Date de publication : 1 juin 2006

Pagination : 151-179

ISSN : 0246-8743

Référence électronique

Anna Wierzbicka, « Les universaux empiriques du langage : tremplin pour l'étude d'autres universaux humains et outil dans l'exploration de différences transculturelles », Linx [En ligne], 54 | 2006, mis en ligne le 01 août 2007, consulté le 20 avril 2019. URL : http://journals.openedition.org/linx/517 ; DOI : $10.4000 / \operatorname{lin} x .517$ 


\title{
Les universaux empiriques du langage : tremplin pour l'étude d'autres universaux humains et outil dans l'exploration de différences transculturelles
}

\author{
Anna Wierzbicka \\ Australian National University - Canberra
}

Traduit de l'anglais par Bert Peeters (University of Tasmania)

\section{Introduction}

Deux phrases suffisent à résumer l'essentiel de ma pensée : premièrement, qu'il est impossible de formuler des universaux de la culture ou de la cognition en l'absence d'universaux du langage bien établis, et deuxièmement, que le recours à des universaux du langage est tout aussi indispensable afin d'obtenir des généralisations valables portant sur les différences transculturelles. L'idée est simple et peut être élaborée à l'aide des assertions suivantes :

- La quête des propriétés, universelles ou bien spécifiques, de la cognition humaine est une quête de généralisations.

- Ces généralisations, pour être exprimées, nécessitent le recours à l'une ou l'autre langue.

- Toute langue comporte des façons de penser qui lui sont propres, qui manquent d'universalité. 
- Formuler, sans esprit critique, des universaux hypothétiques, en s'appuyant sur une langue naturelle, par exemple l'anglais ou le français, c'est s'exposer au risque de les défigurer en leur imposant la perspective implicite dans la langue utilisée ; risque qui, par ailleurs, existe également dans la description de différences culturelles.

- Une langue servant d'outil descriptif ne manquera pas d'introduire des partis pris, à moins qu'elle ne soit universelle, c'est-à-dire exempte de rapports avec une culture et une société particulières.

- D’où la conclusion qu'il est impossible de formuler des universaux de la culture ou de la cognition dignes de ce nom à moins qu'on ne dispose d'une langue universelle; et, de même, que seule une langue universelle permet de formuler, indépendamment de toute culture spécifique, des généralisations portant sur des cultures différentes.

Reste à savoir, bien entendu, s'il est possible qu'une langue soit universelle. Gardons à l'esprit qu'au cours des siècles plusieurs penseurs, et rêveurs, ont essayé de construire des langues présumées universelles (voir, p.ex., l'aperçu récent dans Umberto Eco 1994) - et qu'aucune langue proprement universelle, qui se prête à la communication transculturelle ou à la description « culturellement neutre » de la nature humaine, de la cognition humaine, et des cultures humaines, n'est jamais issue de ces tentatives, qui sont restées vaines. Paradoxalement, le vieux rêve d'une langue universelle a conduit à l'élévation de l'anglais au rang de lingua franca globale, utilisée de plus en plus souvent dans la communication transculturelle, les relations internationales, les affaires, la technologie, et la circulation des idées dans toutes les sciences, y inclus la psychologie et l'anthropologie.

Comme lingua franca universelle, l'anglais a fait ses preuves dans plus d'un domaine. Mais il est évident qu'en tant qu'instrument de communication en psychologie culturelle ou en anthropologie psychologique il laisse à désirer, simplement parce que - comme toute autre langue naturelle - il exprime un univers sémantique particulier, culturellement spécifique. L'usage extensif des mots anglais right et wrong dans la littérature sur les valeurs humaines, la culture et le développement moral, les croyances morales etc. illustrent de façon très nette les pièges d'une quête d'universaux culturels ou cognitifs à travers la langue anglaise ; contrairement aux concepts universaux BIEN et MAL, les mots right et wrong expriment des concepts «indigènes » de l'anglais influencés par une histoire et une culture tout aussi «indigènes ». L'admission, parmi les « universaux humains », du concept on ne peut plus anglo-saxon de «fairness » (voir Pinker 2002) constitue un exemple tout aussi éloquent.

Qu'est-ce qui nous permet de dire que BIEN et MAL sont des universaux, tandis que right et wrong, ou fair et unfair ne le sent pas ? Ce qui nous permet de le dire, ce sont les enquêtes approfondies, portant sur plusieurs langues, menées depuis des années par de nombreux linguistes travaillant dans le cadre de le théorie MSN (voir en particulier Goddard et Wierzbicka réd. 1994, 2002). Une première hypothèse avancée ici est qu'une langue universelle, «culturellement neutre », peut être construite à l'aide d'universaux empiriques du langage tels que les concepts BIEN et MAL, et une soixantaine d'autres, y compris, par exemple, SAVOIR et PENSER, VOULOIR et SE SENTIR, DIRE et FAIRE, ARRIVER, QUELQU'UN, QUELQUE CHOSE et GENS, etc. (cf. Tables 1 et 2 ci-dessous; pour plus de renseignements, voir Wierzbicka 1996, Goddard 1998, 
Goddard et Wierzbicka réd. 1994, 2002, Peeters réd. 2006). Une deuxième hypothèse est que, dans l'ensemble, cette langue a d'ores et déjà été construite, de sorte que l'idée d'une «langue universelle» n'appartient plus au royaume des mythes mais à la réalité de tous les jours. Ce que nous appelons la «métalangue sémantique naturelle», ou MSN, sert depuis de nombreuses années d'outil pratique dans l'exploration de nombreuses langues et cultures (voir les renvois dans les Références).

\section{Table 1 : Table des primitifs conceptuels, version anglaise}

Substantifs :

Déterminants :

Quantificateurs :

Attributs :

Prédicats mentaux :

Discours :

Actions, événements, mouvement :

Existence et possession :

Vie et mort :

Concepts logiques :

Temps :

Espace :

Intensificateur, augmentateur :

Taxonomie, partonomie :

Similarité :
I, YOU, SOMEONE, SOMETHING, PEOPLE, BODY THIS, SAME, OTHER

ONE, TWO, SOME, MUCH/MANY, ALL

GOOD, BAD, BIG, SMALL

THINK, KNOW, WANT, FEEL, SEE, HEAR

SAY, WORDS, TRUE

HAPPEN, MOVE

THERE IS, HAVE

LIVE, DIE

NOT, MAYBE, CAN, BECAUSE, IF

WHEN, NOW, AFTER, BEFORE, A LONG TIME, A SHORT TIME, FOR SOME TIME, MOMENT WHERE, HERE, ABOVE, BELOW, FAR, NEAR, SIDE, INSIDE, TOUCH

VERY, MORE

KIND OF, PART

LIKE

Table 2 : Table des primitifs conceptuels, version française (cf. Peeters réd. 2006)

Substantifs :

JE, TU, QUELQU'UN, QUELQUE CHOSE, GENS, CORPS

Déterminants :

CE, MÊME, AUTRE

Quantificateurs :

UN, DEUX, CERTAINS, BEAUCOUP, TOUT

Attributs :

Prédicats mentaux :

BIEN, MAL, GRAND, PETIT

PENSER, SAVOIR, VOULOIR, SE SENTIR, VOIR, ENTENDRE

Discours :

DIRE, MOTS, VRAI

Actions, événements, mouvement: FAIRE, ARRIVER, BOUGER

Existence et possession :

IL Y A, AVOIR

Vie et mort :

Concepts logiques :

Temps :

VIVRE, MOURIR

NE ... PAS, PEUT-ÊTRE, POUVOIR, À CAUSE DE, SI

QUAND, MAINTENANT, APRÈS, AVANT, LONGTEMPS, PEU DE TEMPS, POUR UN TEMPS, EN UN MOMENT, 
Anna Wierzbicka

Espace :

Intensificateur, augmentateur :

Taxonomie, partonomie :

Similarité :
OÙ, ICI, AU-DESSUS, AU-DESSOUS, LOIN, PRÈS, CÔTÉ, DANS, TOUCHER

TRÈS, PLUS

TYPE DE, PARTIE

COMME

Les primitifs :

- se lexicalisent sous forme de mots, de morphèmes liés ou de phrasèmes ;

- ils peuvent être formellement, c'est-à-dire morphologiquement, complexes ;

- d'une langue à l'autre, ils peuvent avoir des propriétés morphosyntaxiques différentes (et notamment appartenir à des catégories lexicales distinctes) ;

- ils peuvent avoir des variantes combinatoires (des allolexes).

La théorie MSN du langage et de la pensée, d'abord énoncée en 1972 dans mon livre Semantic primitives, et développée ensuite, tout au long des années, en collaboration avec Cliff Goddard, se fonde sur le postulat que le noyau partagé de la pensée humaine se reflète dans le noyau partagé de toutes les langues du monde et se laisse identifier grâce à des enquêtes empiriques d'ordre linguistique. Un postulat concomitant est que ce noyau partagé de toutes les langues et de la pensée humaine, une fois identifié, peut servir de métalangue sémantique naturelle dans la description et l'exploration de façons de penser universelles aussi bien que culturellement spécifiques.

En outre, comme cette métalangue sémantique naturelle correspond au noyau lexical et grammatical que se partagent toutes les langues naturelles, il en existe autant de versions qu'il y a de langues. Cependant, contrairement aux langues naturelles ellesmêmes, dans tout ce qu'elles ont de plus riche et de plus épanoui, ces mini-langues (taillées dans lesdites langues naturelles) se correspondent sémantiquement; ainsi, toutes les langues ont des mots qui correspondent exactement aux mots anglais good et bad (ou aux mots français bien et mal), non pas dans l'ensemble de leurs usages, mais dans les usages illustrés dans des phrases canoniques telles que c'est bien / c'est mal, ou encore il pourra t'arriver quelque chose de bien / de mal.

Autrement dit, en vertu de la théorie MSN, la MSN anglaise, c'est-à-dire la métalangue sémantique taillée dans la langue anglaise et fondée exclusivement sur des universaux linguistiques établis empiriquement, peut servir de métalangue intelligible et néanmoins culturellement neutre dans l'étude des divergences aussi bien que des universaux d'ordre culturel et cognitif. Une MSN russe, malaisienne ou française conviendrait également; mais le rôle de l'anglais dans le monde contemporain fait de la MSN anglaise la lingua franca la plus pratique pour les recherches transculturelles. Nous croyons qu'elle est aussi la métalangue optimale pour l'identification de ce que les anthropologues Quinn et Strauss appellent des «schémas cognitifs partagés qui proviennent d'une expérience partagée, malgré la variabilité et la versatilité dont cette expérience et ces schémas sont susceptibles» (Quinn 2002). Dans ce qui suit, je me propose d'illustrer ces idées à l'aide d'un nombre d'exemples. Je montrerai plus en particulier comment la métalangue sémantique naturelle se prête à la comparaison de divers modèles culturels de l'être humain exprimés dans et transmis par des langues différentes; et comment, en outre, elle se prête à l'identification et à la comparaison de valeurs culturelles exprimées dans des mots-clés. 


\title{
1. L'être humain : un modèle populaire universel
}

«Le concept d'une personne varie-t-il d'une culture à l'autre ?» demandent, dans un article devenu célèbre, Richard Shweder et Edmund Bourne (1982). Leur réponse ne laisse aucun doute: «Evidemment» (p. 153). Dans un autre article, non moins célèbre, Roy D'Andrade (1987) tente d'identifier « un modèle populaire de l'esprit » ('a folk model of the mind'), et de contraster le modèle euro-américain avec un modèle non occidental, plus précisément celui de l'ifaluk. Prenant appui sur les questions soulevées dans ces deux articles, j'aimerais en soulever deux autres : d'abord, celle de savoir s'il nous est donné d'identifier un «modèle populaire de l'esprit» qui soit universel; ensuite, celle de savoir s'il nous est donné d'identifier un modèle populaire universel, ou un modèle culturel, de l'être humain.

A condition de recourir à des universaux du langage empiriquement établis, il nous est possible de répondre à ces deux questions par l'affirmative. Commençons par la première : un modèle populaire universel de l'esprit se dégage de l'ensemble universel des prédicats psychologiques trouvés dans toutes les langues. Il y en a sept: SAVOIR, PENSER, VOULOIR, DIRE, SENTIR, VOIR et ENTENDRE. Les divers modèles culturellement spécifiques sont des élaborations de ce modèle universel partagé, des élaborations que le modèle universel permet de comparer de façon fructueuse.

Où se situe par rapport à ce modèle populaire universel de l'esprit le mot anglais mind? Nous verrons dans quelques instants qu'il en constitue lui-même une élaboration. Aussi vaudra-t-il mieux s'attarder d'abord au modèle universel de l'être humain. Il y a de nouveau un ensemble de prédicats universaux permettant d'identifier ce modèle-là. Il inclut les sept prédicats mentionnés dans ce qui précède, mais il est bien plus riche. Sans prétendre à l'exhaustivité, on peut y distinguer cinq parties ou aspects : un aspect « existentiel », un aspect "psychologique », un aspect «social», un aspect « moral » et un aspect « logique».

\section{Le modèle universel d'un "être bumain "}

\author{
Aspect « existentiel» \\ quelqu'un \\ ce quelqu'un a un corps \\ ce quelqu'un peut vivre \\ ce quelqu'un peut mourir \\ ce quelqu'un peut faire beaucoup de choses \\ beaucoup de choses peuvent arriver à ce quelqu'un \\ Aspect «psychologique » \\ ce quelqu'un peut savoir des choses \\ ce quelqu'un peut vouloir des choses \\ ce quelqu'un peut penser à des choses \\ ce quelqu'un peut sentir des choses (des émotions) \\ ce quelqu'un peut dire des choses
}


Anna Wierzbicka

ce quelqu'un peut voir des choses

ce quelqu'un peut entendre des choses

Aspect « social »

ce quelqu'un peut faire des choses avec d'autres gens

ce quelqu'un peut vivre avec d'autres gens

ce quelqu'un peut dire des choses à d'autres gens

Aspect «moral 》

ce quelqu'un peut faire du bien

ce quelqu'un peut faire du mal

Aspect "logique »

ce quelqu'un peut penser avec des mots comme "à cause de, «si ", «ne...pas", « peut-être »

On le voit : quoiqu'il y ait une variété de modèles culturellement spécifiques de l'être humain, il est clair qu'il y a aussi un modèle populaire (un folk model, au sens que D'Andrade donne à cette expression) qui est remarquablement "épais » (au sense de Clifford Geertz) et riche, et universel. Il suffit, pour identifier ce modèle, d'identifier certaines façons de parler trouvées dans toutes les langues.

Le modèle populaire universel fournit un point de départ solide et fiable permettant d'entreprendre des comparaisons transculturelles. L'aspect « existentiel» $\mathrm{du}$ modèle fournit une base pour l'exploration de diverses ethno-philosophies (y compris, par exemple, des concepts tels que «sort» et « destinée ») ; l'aspect « social », pour l'ethno-sociologie comparative ; l'aspect «moral», pour l'éthique et la religion comparées (cf. Wierzbicka 2001); l'aspect "psychologique", pour l'anthropologie psychologique ; etc.

Ainsi, au lieu d'entreprendre une étude transculturelle de la perception et/ou de la conceptualisation des "couleurs", il est plus profitable d'étudier la sémantique culturelle de la perception visuelle: nous savons depuis pas mal de temps que le concept de «couleur » est étranger à plusieurs cultures, et que beaucoup de langues n'ont pas de mot correspondant, alors que toutes les langues ont un mot correspondant au mot français VOIR (dans un sens particulier) (cf. Wierzbicka 1990, 1996, 1999b ; Lucy 1997). De la même façon, plutôt que de comparer des «émotions » (anglais emotions) au-delà des frontières linguistiques et culturelles, il est plus profitable de comparer les façons dont une personne parle de ce qu'elle ressent, et de s'attacher particulièrement aux «façons de ressentir » apparentées aux façons de penser : une fois de plus, le concept d' " émotion» (emotion) n'est pas un concept humain universel, contrairement à (SE) SENTIR et à PENSER (cf. Wierzbicka 1995, 1999a; Russell 1997). On peut également comparer, d'une culture à l'autre, les façons de parler de sentiments relatifs au corps humain: dans toutes les langues du monde se trouvent lexicalisés les concepts (SE) SENTIR et CORPS (cf. Enfield et Wierzbicka réd. 2002). En revanche, l'exploration des cultures, et de la « nature humaine » elle-même, effectuée à travers le prisme du mot anglais emotion, et le recours à ce mot, non pas à titre d'abréviation commode, mais pour découper la nature à ses jointures, conduit 
inévitablement à une distortion, imputable à nos propres préjugés, de l'image que nous nous faisons de l'être humain dans une culture particulière.

Il est difficile de ne pas évoquer à ce propos ce qu'ont dit naguère Bateson et Mead (1942 : xi), dans l'introduction à leur ouvrage Balinese Character: «Avant toute autre chose, observent-ils, nous savons, au sujet de la relation entre les cultures et les concepts verbaux, que les mots qu'une culture particulière a investis de sens sont, de par l'exactitude de leur pointure culturelle, singulièrement inappropriés comme véhicules de commentaires précis portant sur une autre culture» (propos cités récemment par les anthropologues Miller et Hoogstra 1992 : 94, dans leur contribution à un volume intitulé Nen directions in psychological anthropology). C'est une remarque pertinente pour tous ceux qui recourent à des mots aussi essentiels et aussi transparents (du moins aux yeux de quiconque s'exprime en anglais) que colour, mais aussi emotion, fair et unfair, justice, evidence, common sense, privacy, self-esteem etc. Miller et Hoogstra (ibid. : 95) rappellent que la solution de Bateson et Mead consistait à « éviter le recours aux mots, au profit d'une analyse photographique des cultures». Il va cependant sans dire que l'on ne saurait photographier les idées culturelles d'un peuple au sujet de la vie intérieure des gens. En vue de comprendre ces idées-là, nous n'avons à notre disposition que des moyens linguistiques.

Miller et Hoogstra font en outre valoir que «pour l'ethnographe, comme pour l'enfant, le langage fournit un instrument crucial dans l'apprentissage des sens culturels ». Elles continuent en disant que «les structures linguistiques fournissent à l'ethnographe un point d'entrée dans les systèmes culturels (...) - et un guide pour la collection d'échantillons discursifs interprétables...» (ibid.). Il est vrai, je crois, que les structures linguistiques - les mots, les expressions, les proverbes, etc. - fournissent à l'ethnographe un point d'entrée dans les systèmes culturels; mais quelle est la langue à utiliser lors de l'interprétation de ces mots, de ces expressions et de ces proverbes? Voilà, me semble-t-il, la question cruciale. A les interpréter tout simplement en anglais ou en français, dans tout ce que ces langues ont de plus riche, nous entrons dans ces systèmes culturels accablés de notre bagage culturel personnel - et nous sommes incapables de les comprendre du point de vue des « autochtones ».

D’aucuns voient dans cet état de choses une conséquence inévitable du "paradoxe de l'observateur»: «Bien sûr », disent-ils, "nous finirons par défigurer quelque peu l'objet de nos enquêtes en l'analysant d'un point de vue qui nous est propre, mais il ne peut en être autrement». Or, il n'y a rien de plus faux. Il suffit d'adopter comme outil de base l'ensemble des concepts humains universaux empiriquement établis. Le recours à cet outil, à ces concepts universaux, permet notamment d'articuler un modèle populaire universel de ce qui constitue une personne, un être humain, et d'utiliser ce modèle comme point de repère dans l'étude des façons dont « le concept de personne varie d'une culture à l'autre».

Ayant observé correctement que «les comparaisons transculturelles sont souvent implicites, la culture de l'anthropologue servant de critère muet mais réel par rapport auquel s'évalue l'autre'» (p. 223), des anthropologues Munroe et Munroe (2001) répètent, sans les discréditer, les conclusions du psychologue Paul Ekman et de ses associés, conclusions en vertu desquelles « les expressions faciales aussi bien que la reconnaissance des émotions 'fondamentales' (joie, tristesse, colère, peur, surprise, et dégoût) n'étaient qu'à peine différentes dans cinq nations modernes (l'Argentine, le Brésil, le 
Chili, le Japon et les États-Unis) et deux tribus traditionnelles (le peuple fore et le peuple dani de la Papouasie-Nouvelle-Guinée) ». Munroe et Munroe semblent être inconscients du fait qu'Ekman a fait exactement ce qu'ils condamnent avec tant d'éloquence : il a pris sa propre culture comme critère muet mais réel par rapport auquel s'évalue non seulement l'autre', mais aussi la nature humaine en général. Ekman n'est pas sans savoir (puisqu'il l'a confirmé dans ses publications) que ni le peuple fore ni le peuple dani n'ont de mots pour l'ensemble des « émotions humaines fondamentales » dont il affirme la réalité ; mais cela ne l'empêche pas de postuler que les termes auxquels il recourt - même s'ils n'ont pas d'équivalents dans d'autres langues - dénotent, de façon claire et univoque, «des émotions humaines universelles ».

De façon plus générale, il arrive bien trop souvent que les preuves manifestes, d'ordre linguistique, de catégorisation non identique des «émotions» humaines à travers les langues du monde soient simplement jugées hors de propos, et que le vocabulaire anglais des émotions soit adoptée comme point de départ. Les expressions faciales des sociétés les plus diverses sont conceptualisées à l'aide d'un ensemble invariable de mots anglais (dans des conditions de choix forcé ; cf. Van Brakel 1994, Russell 1993), et la conclusion à laquelle on aboutit ensuite est que ces conceptualisations ( « colère », « joie », etc.) expriment aptement ce que ressentent les ressortissants de ces sociétés... Ensuite paraissent des livres influentiels (p.ex. Pinker 2000), dont les auteurs reprennent à leur compte des conclusions telles que celles d'Ekman, et c'est ainsi que se trouve perpétué, et de plus en plus enraciné dans la mythologie scientifique, le mythe des émotions humaines universelles, comparable au mythe des « universaux de couleur » (cf. Wierzbicka 1990, 1999b ; Lucy 1997).

Dans l'introduction de leur recueil d'articles intitulé La psychologie de l'expérience culturelle, les anthropologues Holly Mathews et Carmella Moore (2001:1) écartent (en leur propre nom et au nom des auteurs des études qui suivent) la thèse de l'incommensurabilité psychologique de cultures différentes et mettent en évidence l'importance du « vécu d'individus actifs et inspirés ». Elles continuent en disant que «les deux dernières décennies ont vu l'approche constructiviste du sens et de la pratique culturelle empiéter sur d'autres approches jusqu'alors prévalentes, ce qui a poussé beaucoup de chercheurs à exagérer la magnitude et l'importance de la diversité culturelle et à conclure, souvent sur des bases empiriques relativement faibles, que chaque culture construit sa propre psychologie » (ibid., italiques ajoutées).

Je conviens du fait que la magnitude et l'importance de la diversité au niveau de la psychologie culturelle humaine ont parfois été exagérées; et je rejette, à l'instar de Mathews et Moore, la «thèse de l'incommensurabilité culturelle et psychologique ». Je n'ai jamais cessé de répéter que les différents systèmes conceptuels associés à des langues et à des cultures différentes partagent un noyau commun et que ce noyau partagé fournit un commun diviseur permettant d'entreprendre des comparaisons transculturelles. Il faut cependant faire remarquer que la magnitude et l'importance de la diversité en matière de psychologie culturelle humaine ont encore plus souvent été sous-estimées. Ainsi, quand Pinker (1999) affirme que la vie mentale n'est pas influencée par des langues individuelles, ou quand il déclare (dans Pinker 2000) n'avoir jamais rencontré, dans quelque langue étrangère que ce soit, de terme d'émotion dont le sens ne soit pas immédiatement reconnaissable, il est clair que la magnitude et l'importance de la diversité sont loin d'être exagérées ! 
Il me semble que, pour apprécier à sa juste valeur la magnitude de la diversité culturelle qui existe dans l'expérience intérieure des êtres humains, il faut avant tout puiser à deux sources. Il faut d'abord examiner la façon dont des ressortissants de cultures différentes parlent de leurs expériences profondes, c'est-à-dire étudier les vocabulaires indigènes des émotions et de la vie intérieure ; il faut ensuite - j’y reviendrai plus tard - récolter des témoignages personnels de divers vécus indigènes.

Miller et Hoogstra (1992: 92) notent que «l'apprentissage des processus interprétatifs du discours et des pratiques situées pose des problèmes non seulement à l'enfant mais aussi à l'ethnographe». Elles observent que l'un de ces problèmes « découle du fait que l'ethnographe, contrairement à l'enfant, a déjà 'appris' une culture »; il s'ensuit que «l'ethnographe court le risque, inévitable, de confondre son propre cadre interprétatif avec le cadre autochtone » (ibid.). A mon avis, l'ethnographe qui décrit et interprète le discours et les pratiques d'une autre culture en recourant à l'anglais scientifique fait beaucoup plus que s'exposer à un risque; il tombe immanquablement dans le piège qu'il a lui-même tendu. Comment pourrait-il en être autrement si on choisit d'utiliser des mots anglais complexes et culturellement spécifiques tels que mind, self, emotion, fairness, autonomy, privacy, etc. afin de décrire et d'interpréter la vie et les façons de penser d'individus à qui ces concepts sont étrangers ?

Les mêmes auteurs renvoient à ce sujet à une remarque de Clifford Geertz, selon laquelle « des formes culturelles livrent leurs propres interprétations pourvu que l'on soit capable d'y accéder » (ibid.). A mon avis, Geertz a tout à fait raison. Des motsclés culturels tels que mind en anglais, maum en coréen, kokoro en japonais et duša en russe, que j'analyserai sous peu, permettent effectivement de mieux comprendre des façons de penser «indigènes »- pourvu que l'on soit capable d'accéder à leur sens. Depuis de nombreuses années, mes collègues et moi soulignons qu'il est possible d'accéder à des "formes culturelles » à la Geertz en s'appuyant sur des concepts universels partagés, qui permettent de saisir le point de vue autochtone et de le faire connaitre sans distorsions du reste du monde (cf. Shore 1996).

Miller et Hoogstra (1992: 92) fournissent l'évaluation suivante: «L'approche de Geertz est louable dans la mesure où se trouve reconnue la nécessité d'un cadre pour les comparaisons transculturelles. Elle laisse à désirer dans la mesure où l'auteur n'arrive pas à identifier un moyen formel, valable au-delà des frontières culturelles, permettant d'arriver au but qu'il s'est posé ». A l'instar de notre éminent confrère, mes collègues et moi professons, une fois de plus depuis de nombreuses années, qu'il est nécessaire d'avoir un cadre pour les comparaisons transculturelles. A la différence de celui de Geertz, notre cadre à nous n'est pas restée lettre morte : il existe, et il nous permet d'arriver au but que nous nous sommes posé.

\section{Quatre modèles culturels différents de l'être humain : anglo, coréen, japonais, et russe}

Les données linguistiques confirment que, dans de nombreuses cultures, l'être humain se compose, pour ainsi dire, de deux parties : une partie visible, à savoir le corps, et une partie invisible. La partie visible appartient au modèle universel de l'être humain et est lexicalisée dans toutes les langues: au mot corps du français 
correspondent l'anglais body, le russe telo, le coréen mom, le japonais karada, et ainsi de suite. La partie invisible, quant à elle, est conceptualisée différemment d'une langue ou d'une culture à l'autre.

Commençons par l'anglais. Le modèle culturel prédominant qui s'y trouve reflété conçoit l'être humain comme ayant deux parties, à savoir un corps (body) et un esprit (mind). D'autres modèles, moins répandus, font état d'un cœur (heart) et d'une âme (soul), l'un et l'autre coexistant avec le corps (body). L'étude des textes révèle qu'à l'époque de Shakespeare le modèle prévalent était différent : c'était certes un modèle à deux parties, mais les deux parties constitutives de l'être humain étaient le corps et l'âme (" the body and the soul»). Or, le modèle shakespearien a été délogé du centre de la psyché collective des anglophones et a été remplacé par le modèle du corps et de l'esprit ("the body and the mind»). Ce qui nous permet de le dire, c'est la fréquence relative des mots soul et mind en anglais parlé contemporain : à en croire le corpus COBUILD de l'anglais britannique parlé, il y a 257 occurrences du mot mind sur un million de formes lexicales, alors qu'il n'y en a que 10 du mot soul. La différence est spectaculaire. Par ailleurs, l'importance du «mind» - et du modèle «body and mind»- dans la culture anglo contemporaine se dégage clairement des innombrables titres de livres récents, dont plusieurs d'ordre philosophique et scientifique, tels que, par exemple, Problems of mind and matter, Mapping the mind, Evolution and the human mind, The history of the mind, Body and mind, Mind and body, The Japanese mind, voire The mind of God...

Afin de bien comprendre le modèle anglais du corps et de l'esprit (mind), et en vue de l'expliciter dans une perspective universelle, il nous faut analyser le sens du mot mind en concepts humains universels. Voici comment on pourrait s'y prendre :

$\underline{\text { Le « mind » anglais }}$

l'une de deux parties d'une personne

les gens ne peuvent pas voir cette partie

à cause de cette partie, une personne peut penser à des choses

à cause de cette partie, une personne peut savoir des choses

On se gardera de confondre le mot personne tel qu'il est utilisé ici et tel qu'il sera utilisé dans les formules ci-dessous (c'est-à-dire précédé d'un article indéfini) avec l'élément primitif PERSONNE, qui est un allolexe (une variante) du primitif QUELQU'UN. Le mot personne est polysémique, comme l'est d'ailleurs le mot person en anglais. Dans des formules rédigées dans la version courante (2006) de la MSN, personne 'être humain' serait muni du symbole $[\mathrm{M}]$, signifiant «molécule sémantique ». Par ailleurs, les formules montrent à quel point la causalité est omniprésente dans les façons de parler et de penser des locuteurs, quelles que soient la langue et la culture dont ces façons de parler et de penser relèvent.

Dans mon ouvrage Semantics, culture and cognition (Wierzbicka 1992), je me suis efforcée de montrer que le sens précis du mot mind auquel nous venons de faire allusion ne s'est manifesté et établi en anglais qu'au cours du dix-neuvième siècle, en conjonction avec un modèle culturel qui conçoit l'être humain comme l'union d'un corps et d'un esprit (au sens de l'anglais mind). Etant donné l'importance, dans la littérature philosophique et scientifique moderne, du concept populaire que l'on identifie communément à l'aide du mot mind, il est crucial de se rappeler que dans 
d'autres langues et dans d'autres cultures les êtres humains sont envisagés à travers le prisme d'autres modèles culturels. En dépit des critiques familières, souvent hâtives, du "dualisme occidental (dit cartésien) », un grand nombre de ces modèles sont eux aussi dichotomiques - quoique différents du modèle anglais du corps et de l'esprit (mind). Ainsi, en coréen (Yoon 2003), l'être humain est également conçu comme comportant deux parties, dites mom et maum; et alors que le mot mom correspond rigoureusement à des mots tels que body et corps, le concept qu'exprime le mot maum est très différent de celui qu'exprime le mot mind, de sorte que, plus souvent que non, l'anglais heart 'cœur' fournit une meilleure traduction que l'anglais mind. Or, en coréen comme en anglais, il y a de nombreux livres portant notamment sur des sujets scientifiques et/ou médicaux, dont les titres révèlent que l'être humain se compose d'un mom et d'un maum. On a par exemple (cf. Yoon 2003) des ouvrages tels que La santé du corps et la santé $d u$ maum, La biologie du corps et du maum, Les maladies $d u$ corps et $d u$ $\underline{\text { maum }}$, Le maum et le corps. Yoon observe très justement qu'il y a « une vaste littérature sur le sujet 'mom et maum'».

Par opposition au mind de l'anglais, le maum du coréen est un siège d'émotions, de motivation, et de «bonté» de l'être humain. Le mot coréen le plus proche de l'anglais mind n'est pas maum, mais meli - littéralement 'tête'. C'est à la " tête » (au meli) plutôt qu'au maum que se rapportent avant tout les fonctions intellectuelles et cognitives. Cependant, les deux entités qui constituent le modèle dichotomique fondamental de l'être humain en coréen ne sont pas le mom et le meli, le corps et la tête, mais le mom et le maum, le corps et... le maum - le siège des émotions, l'origine de la motivation, la source de la bonne volonté. Le maum est le centre dynamique - émotionnel et motivationnel - d'une personne, qui différencie l'être humain d'autres êtres animés. On peut expliciter le concept de maum à l'aide de la formule ci-dessous, adaptée de Yoon (2003). A des fins de comparaison, quelques-unes des composantes ont été mises en relief :



Passons au kokoro du japonais (pour plus de détails, voir Hasada 2000). Il importe de souligner d'emblée que, différent du mind et du maum, le kokoro fait lui aussi partie d'un modèle dichotomique, à savoir le modèle de l'être humain prévalent dans la culture japonaise, un modèle qui comporte un corps (karada) et un kokoro. Une fois de plus, le modèle populaire prédomine dans la science et la philosophie aussi bien que dans la vie quotidienne. Hasada rapporte les propos d'un psychologue clinique disant que, dans sa profession, il s'occupe du kokoro des gens. Cependant, l'objet d'étude des 
psychologues japonais diffère manifestement de celui des psychologues coréens, puisque kokoro et maum sont loin d'avoir le même sens. Il diffère aussi de l'objet d'étude de ceux qui se donnent la tâche d'étudier l'esprit ou «the mind» (voire l'esprit dit bumain). En fait, quand un spécialiste des sciences cognitives tel que Stephen Pinker (2000) se propose d'expliquer «comment fonctionne l'esprit», il s'attarde non pas au «maum» ou au «kokoro» des gens (comme le ferait un spécialiste coréen qui écrit en coréen, ou un spécialiste japonais qui écrit en japonais) mais il se consacre à l'étude de leur « mind». Ce qui, détail piquant, nous conduit à suggérer une réponse à la question de Pinker qui est en contradiction avec sa théorie d'un « esprit humain » entièrement uniforme: l'« esprit» fonctionne souvent conformément à ce que dicte la langue maternelle du chercheur...

Contrairement au maum, le kokoro du japonais est avant tout un siège d'émotions, et aussi une source d'attention culturellement valorisée aux autres, et d'empathie avec autrui. Ainsi (Hasada 2000), la phrase Les randonneurs sans kokoro sèment leurs parcours d'ordures implique que les randonneurs agissant de la sorte ne pensent pas aux autres et n'ont cure que d'autres "pourraient se sentir mal à cause de cela» (je parle ici en MSN). Autre exemple (ibid.), tiré d'une émission télévisée japonaise :

Le vingt-et-unième siècle devrait être le siècle du kokoro.

Ne manquons pas de faire des rencontres.

$\mathrm{Si}$, au lieu d'être proclamé le "siècle du kokoro", le $21^{\mathrm{e}}$ siècle était proclamé le « siècle du mind», l'essentiel ne serait pas de «faire des rencontres »; ce serait plutôt une invitation à stimuler le cerveau avec de nouvelles pensées et de nouveaux savoirs.

Hasada (2000) fait remarquer que «le kokoro est très important dans les arts japonais traditionnels tels que la cérémonie du thé, l'arrangement des fleurs, et le théâtre kabuki ». Elle ajoute que «même un produit d'apparence impeccable peut être évalué négativement s'il n'émane pas le kokoro de son créateur». En outre, contrairement au mind de l'anglais, le kokoro du japonais peut être « froid» (tsumetar); la connotation péjorative de l'expression «un kokoro froid» souligne l'importance et l'évaluation positive des émotions dans le modèle prévalent de l'être humain au Japon. Par ailleurs, contrairement au maum du coréen, le kokoro ne semble pas être le siège de la motivation et de la volonté. Ce rôle revient à un autre organe, à savoir le hara - c'està-dire le 'ventre'. "Ce n'est pas aux autres que pensent les gens lorsqu'ils pensent dans leur hara», écrit Hasada (2000); penser aux autres est une question de kokoro. «Ce qu'ils pensent dans leur hara se rapporte à leurs intentions ou à leurs désirs, à ce qu'ils veulent faire ». Mais ce n'est pas le bara qui, dans le modèle dichotomique de l'être humain chez les Japonais, est le pendant invisible du corps, mais le kokoro. En coréen, d'autre part, il n'y a pas de contrepartie pour le hara, quoiqu'il y ait un autre concept culturel d'importance, à savoir le kasum (littéralement le 'cœur'). Ainsi, en coréen, ce sont la volonté et la motivation qui sont liées au pendant invisible du corps, c'est-àdire au maum; en japonais, le pendant principal du corps, à savoir le kokoro, est lié avant tout aux émotions.

Un dernier détail qui mérite d'être relevé est que le kokoro japonais est insondable, alors que le maum coréen ne l'est pas. Yoon (2003) fait valoir qu'en coréen, c'est le kasum ou le cœur, plutôt que le maum, que l'on construit volontiers comme étant insondable. Mais le kasum n'est pas l'une des «deux parties d'une personne», 
contrairement au kokoro. Cela signifie que le «caractère caché » de la vie intérieure, et particulièrement des émotions, d'une personne est plus important dans le modèle culturel japonais d'un être humain que dans le modèle correspondant du coréen. La formule ci-dessous s'inspire de celle que fournit Hasada (2000).

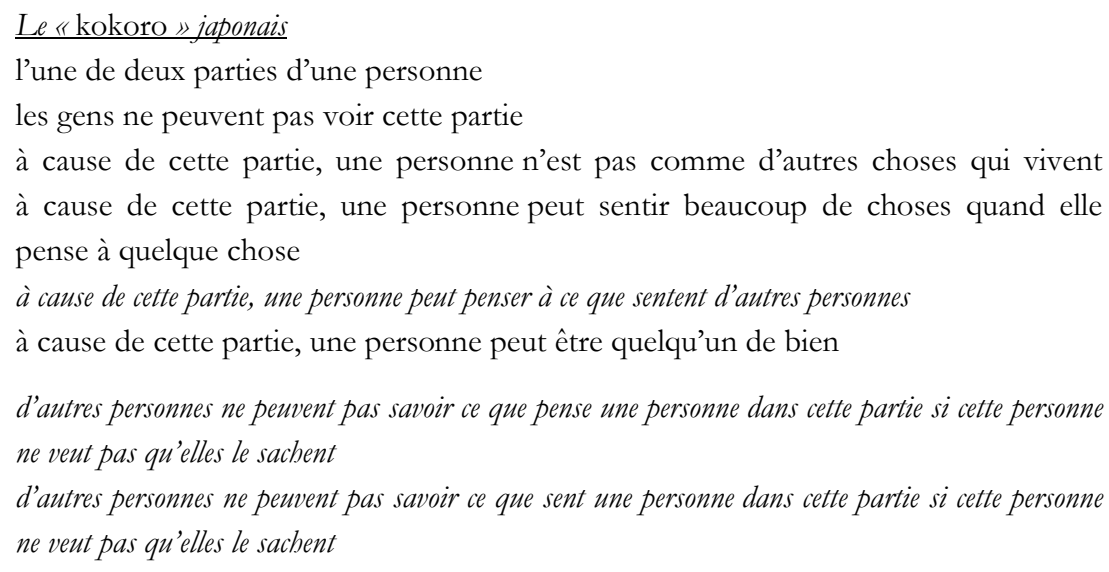

Pour compléter notre aperçu, voici finalement quelques réflexions sur le russe, langue qui, comme l'anglais, le coréen et le japonais, construit l'être humain de façon dichotomique. Hormis un mot pour le corps (telo), le russe dispose d'un mot très commun pour ce qui en est le pendant invisible, à savoir duša. Ce dernier sert normalement de traduction à l'anglais soul, encore que, dans des traductions du russe, on lui fasse souvent correspondre les mots beart ou mind. (Pour une excellente étude ethnographique du concept russe de «duša » et de sa signification au sein de la culture russe, voir Pesmen 2000). La formule proposée ci-après s'inspire de celle donnée dans mon ouvrage Semantics, Culture and Cognition (Wierzbicka 1992) mais est significativement modifiée.

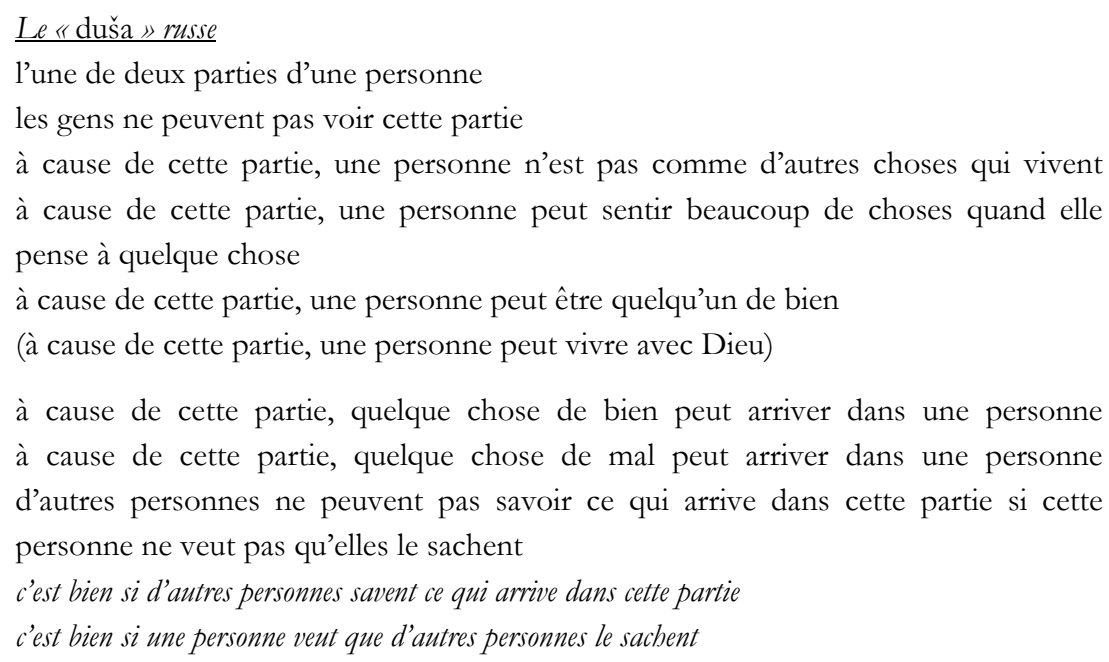

Pour les croyants, le concept de duša est relié au concept de Dieu, comme le montre la composante entre parenthèses («à cause de cette partie, une personne peut 
Anna Wierzbicka

vivre avec Dieu ») ; les parenthèses indiquent que la composante n'est pas essentielle elle manque dans l'usage que font de ce mot les non-croyants. Pour ceux-ci comme pour les croyants, le concept de $d u s_{a}$ e est relié à des émotions diverses, à la moralité, à la spiritualité. C'est une espèce de théâtre où se manifestent les forces du bien et du mal ; et même si, d'habitude, d'autres gens ne savent pas ce qui arrive dans le duša d'une personne, il est bon qu'ils le sachent, et il est bon qu'on veuille que d'autres le sachent. Le $d u s^{\circ} a$ d'un être humain est, pour ainsi dire, ce qui lui permet d'établir des rapports avec autrui. Ce trait intersubjectif, qui est probablement ce que le $d u \stackrel{s}{a} a$ russe a de plus distinctif, le relie en outre à cet idéal culturel que les Russes appellent obščnie, à savoir les entretiens à cœur ouvert auxquels les immigrés russes vivant dans des pays de langue anglaise attachent tellement d'importance: «Russkie ne mogut žit' bez obščenia ", 'Les Russes ne sauraient vivre sans obščnie'. C'est une assertion qui fait écho à celles qui surgissent fréquemment dans des interviews ethnographiques effectuées en Russie, lors desquelles, à maintes reprises, des interviewés déclarent que, plus que tout autre chose, ils estiment les moments d'obšcenie (cf. Pesmen 2000 : 164169 ; voir aussi Wierzbicka 2003).

\section{Deux types de preuves indispensables : « objectives » et « subjectives »}

Les «formes culturelles» dont Geertz a dit qu'elles «livrent leurs propres interprétations pourvu que l'on soit capable d'y accéder» incluent des concepts-clés culturels tels que ceux qu'encodent les mots mind, maum, kokoro and duša. Je me suis efforcée de montrer qu'il nous est possible d'accéder à leurs interprétations légitimes à condition d'étudier leur usage dans la langue de tous les jours, et à condition de les expliciter à l'aide de concepts humains universels. Pour éviter toute confusion entre le sens courant et le sens étymologique ou bien les constructions culturelles nonsémantiques, il sera bon de s'assurer au préalable d'une bonne formation en analyse sémantique. Et s'il est clair que le chercheur qui entreprend l'analyse a un avantage indéniable s'il est en outre locuteur natif et «initié culturel » (à la façon d'une KyungJoo Yoon explorant le concept coréen du «maum» et d'une Rie Hasada étudiant le concept japonais du «kokoro»), il n'est pas nécessaire que l'on soit l'un ou l'autre, puisque le recours à des concepts humains universels réduira au minimum le risque que le chercheur perde le sens des intuitions de ceux qui vivent au sein de la culture donnée, dans la mesure où les descriptions qui s'appuient sur des concepts de ce type sont toujours formulées dans une langue naturelle suffisamment simple pour faire l'objet de discussions avec des informateurs natifs ou pour être rapprochées d'intuitions natives.

Ainsi, sans être ni locutrice native ni « initiée culturelle », Harkins (2001) a eu un recours systématique à des concepts universels au moment d'explorer les expériences émotionnelles du peuple arrernte de l'Australie centrale, et ce faisant a garanti le succès de l'entreprise. Dans la ville d'Alice Springs, elle a consulté trois locutrices natives de la langue arrernte, toutes d'âge mûr et exerçant une profession, et elle leur a parlé aussi bien en arrernte qu'en anglais aboriginal. Ses observations incluent l'assertion que voici (p. 212 ; traduction française) : 
Ma petite étude (...) a mis en évidence quelques-uns des avantages pratiques de l'approche MSN, qui a non seulement facilité la discussion et la compréhension transculturelles de la vie et du comportement émotionnels de personnes vivant dans un contexte culturel particulier, mais qui a en outre fourni un instrument permettant d'expliciter les contenus sémantiques dans la langue cible. La métalangue sémantique naturelle est un outil pratique dont peuvent se servir les enquêteurs aussi bien que les informateurs, et ce dans leur propre langue et dans leur propre contexte culturel.

Loin de moi l'idée - sur ce point je suis tout à fait d'accord avec Harkins - que tous ceux qui s'intéressent à la sémantique culturelle ou à l'anthropologie psychologique devraient s'approprier la méthode qu'elle a adoptée. Mais je n’hésiterai pas à recommander que les méthodes analytiques de chercheurs désireux de comprendre une culture qui n'est pas, ou qui n'est pas devenue, la leur, doivent aller de pair avec une sollicitation des expériences et des intuitions des « autochtones ». C'est la raison pour laquelle j'attache peu de crédibilité aux assertions de certains chercheurs (particulièrement ceux qui sont monolingues et monoculturels) qui croient que l'expérience subjective de différences dans les façons de penser et de sentir caractéristiques de langues différentes n'a pas d'importance, et que ces différences «ne doivent pas être exagérées» (voir p.ex. Pinker 1999, 2000, 2002). Au contraire, l'importance de l'expérience subjective de ceux qui sont bilingues et biculturels ne doit pas être sous-estimée.

Pour ceux qui ont une connaissance approfondie d'au moins deux langues et cultures, il va normalement sans dire que les liens entre la langue que l'on parle et les façons de penser sont inextricables, et que des langues différentes sont liées à des façons de penser différentes (cf. Hunt et Banaji 1987). Semer le doute sur la validité de ces liens en invoquant un soi-disant manque de preuves, c'est ne pas comprendre la nature exacte des preuves que l'on peut avancer. A cet égard, citons Merlin Donald, psychologue cognitif et auteur d'un ouvrage intitulé Un esprit on ne peut plus rare: l'évolution de la conscience bumaine:

Il est inacceptable d'écarter, pour des raisons méthodologiques, des témoignages subjectifs quand en réalité ils sont écartés parce qu’ils montrent avec une clarté déconcertante que l'approche des Radicaux [tels que Pinker, A.W.] souffre de problèmes irrémédiables. On ne saurait tout simplement écarter (...) ce que, de façon consensuelle, des témoins intelligents faisant preuve de sens critique nous révèlent au sujet de leurs expériences conscientes, d'autant plus que ces témoignages constituent pour nous une source primaire de données éthologiques. (Donald 2001 : 85).

A mon avis, les "émigrés linguistiques»- ou «language migrants», terme de Mary Besemeres, sont probablement mieux placés que quiconque pour se prononcer avec autorité sur les liens qui existent entre l'expérience subjective d'un individu et la langue (ou bien les langues) qu'il parle. Il me semble que le témoignage des bilingues, et particulièrement celui d'auteurs bilingues qui ont été amenés à scruter leurs expériences personnelles offre une véritable mine d'informations aussi bien pour l'anthropologie psychologique que pour la «philosophie de l'esprit », la psychologie et 
Anna Wierzicka

les sciences cognitives. Voici ce qu'écrit, dans un chapitre intitulé «Une perspective littéraire », Merlin Donald (2001 : 78) :

Les meilleurs écrivains ont poussé l'exploration subjective de l'esprit bien au-delà de ce qui serait acceptable en psychologie clinique ou expérimentale. (...) Les romanciers en particulier explorent souvent nos plus profondes croyances dans le domaine de la conscience. Leurs représentations constituent une vaste collection, peu systématique, de phénomènes vus de l'intérieur; il est permis de croire que, de toutes les descriptions que nous ayons, ce sont elles qui jouissent de la plus grande autorité.

Ce qui est vrai dans le cas des meilleurs romanciers l'est également dans celui des meilleurs autobiographes. Aussi serait-il insensé, si nous voulons sonder les pensées et les émotions de personnes bilingues qui ont voyagé au-delà des frontières linguistiques et culturelles, de vouloir ignorer, dans les paroles de Donald, « de toutes les descriptions que nous ayons, [celles] qui jouissent de la plus grande autorité ». De ces témoignages venant d'individus qui sont à même de puiser dans leur propre vécu afin de comparer deux types d'expériences intérieures liées à deux langues différentes, il nous est possible de tirer de nombreuses et de riches leçons quant à la nature des liens entre l'expérience intérieure et le langage en général.

En dépit de certaines tentatives récentes visant à discréditer les assertions pénétrantes d'un Humboldt, d'un Sapir et d'un Whorf sur la relativité des mondes conceptuels où vivent des locuteurs de langues différentes, des enquêtes sémantiques rigoureuses telles que celles entreprises au sein du cadre théorique MSN en confirment la validité, et les corroborent à l'aide d'analyses sémantiques détaillées et approfondies. Les témoignages fondés sur l'expérience subjective de personnes bilingues, et surtout d' «émigrés linguistiques », apportent une confirmation supplémentaire. S'attardant en particulier aux expériences de l'écrivain Eva Hoffman, Besemeres fait ainsi valoir que le vécu subjectif des "émigrés linguistiques » justifie la thèse humboldtienne de la relativité linguistique et renforce l'observation du grand linguiste allemand selon laquelle l'apprentissage d'une langue étrangère revient dans certains cas à «l'acquisition d'une nouvelle perspective se surajoutant à la Weltanschanung déjà en place ».

Lost in translation: A life in a new language ('Perdu en traduction: Une vie dans une nouvelle langue'), mémoire d'Eva Hoffman, auteur canadien de naissance polonaise, montre ce qui arrive quand un individu se trouve transplanté de façon abrupte dans une autre culture et une autre langue, et la plupart des observations portant sur ses expériences confirment la thèse de Humboldt. Ayant quitté la Pologne pour s'établir au Canada, ayant appris à 'vivre' en anglais, la jeune Hoffman a 'acquis une nouvelle perspective'; mais c'est une perspective qui, en même temps, plutôt que d'être purement 'surajoutée', était nourrie de sa perspective antérieure de jeune Polonaise.

En parlant du «changement profond de perspective qui accompagne le changement de langue de l'immigrant», Besemeres observe, toujours par rapport au mémoire d'Eva Hoffman :

On vit et on interprète le monde et l'endroit qu'on y occupe à l'aide de (...) concepts propres à la langue que l'on parle. En émigrant, on découvre qu'il y a des concepts 
dans la nouvelle langue et la nouvelle culture qui ne correspondent pas exactement à ceux dont on a l'habitude. L'immigrant est alors obligé de se 'traduire', de traduire son identité, dans la nouvelle langue.

La nature (en partie) linguistiquement spécifique de l'expérience intérieure de l'individu ressort clairement de l'extrait suivant, rédigé par un autre « émigré linguiste », à savoir Luc Sante :

La première chose à dire en ce qui concerne mon enfance est qu'elle s'est pour la plupart déroulée dans une autre langue. J'ai été élevé en français, et je n'ai commencé d'apprendre l'anglais que vers l'âge de sept ans. Même après, le français a continué à être la langue que je parlais à la maison avec mes parents. [A vrai dire, aujourd'hui encore, je ne leur parle qu'en français.] Or, ce fait influence inévitablement mes souvenirs d'enfance et la façon dont j'évoque cette période de ma vie, puisque j'écris et, plus encore, je réfléchis en anglais. Il y a des états d'esprit, il y a même des gens et des événements, qui me semblent inaccessibles en anglais, puisqu'ils sont définis par la langue à travers laquelle je les ai perçus. Ma deuxième langue a fini par devenir mon outil principal, celui qui me permet de gagner ma vie, et elle est proche de ce qui, dans mon for intérieur, constitue le noyau de mon identité. Mais ma première langue n'est jamais très loin, et règne seule dans un domaine plus primal.

A mon avis, des témoignages subjectifs de ce type devraient obliger quiconque s’intéresse aux variétés de l'expérience humaine, aussi bien que quiconque s'intéresse à la nature humaine et à "l'esprit humain", à être aussi attentif que possible aux différents vocabulaires de l'expérience que l'on trouve dans des langues différentes, plutôt que de n’y voir que « de simples différences lexicales ».

Comme l'affirment les auteurs bilingues, et d'autres bilingues (en particulier les " émigrés linguistiques »), des mots différents se rattachent en ce qui les concerne à des modes d'expérience différents et à des façons de penser différentes. Ces modes d'expérience et ces façons de penser, cristallisés sous forme de mots et d'expressions linguistiquement spécifiques, il importe de les comprendre. Mes collègues et moi faisons valoir depuis des décennies qu'en adoptant comme instrument primaire l'ensemble universel des primitifs conceptuels, il nous est donné d'expliciter la façon dont des sens différents sont encodés dans des langues différentes, et ce sans faire violence à l'expérience de ceux qui voyagent au-delà des frontières linguistiques et culturelles. Il nous est donné en outre d'exposer d'une manière claire et précise la variété et la variabilité des concepts, puisque l'ensemble des concepts universaux nous fournit un commun diviseur permettant de comparer des concepts variables au-delà des frontières linguistiques, des générations, des sous-cultures, des sociolectes, etc.

Je crois que l'une des plus importantes leçons que nous apporte Wittgenstein est exprimée dans le passage ci-dessous, tiré des Investigations philosophiques (Wittgenstein 1961) :

Les aspects des choses les plus importants pour nous sont cachés en vertu de leur simplicité et de leur familiarité. (On est incapable de remarquer quelque chose, parce qu'on l'a toujours sous les yeux.) Les véritables fondements de sa recherche ne 
Anna Wierzibicka

frappent pas du tout l'être humain. À moins que ce fait-là ne l'ait une fois frappé. Et cela signifie: que nous manquons d'être frappés par ce qui, une fois vu, est le plus frappant et le plus puissant.

Ces remarques s'appliquent avant tout à notre langue maternelle : nous sommes souvent incapables d'apercevoir les lunettes que nous portons à longueur de journée. Pour de nombreux chercheurs qui s'expriment en anglais, les mots anglais dont ils se servent le plus volontiers (p.ex. reality, fact, evidence, mind, emotion, anger, self-esteem, fairness, reasonable, rights, privacy, independence, et ainsi de suite) sont simplement invisibles - aussi invisibles que les lunettes qu'on omet d'enlever. Souvent, ces mots deviennent les véritables pierres angulaires de leur enquête - jamais examinées ni jamais aperçues.

Passant d'une métaphore à l'autre, on peut dire qu'entre les explorateurs anglophones de «l'esprit humain » et leur sujet d'étude se dresse la paroi invisible mais colorée - de l'anglais. On se gardera de la réduire à un simple obstacle aux enquêtes scientifiques, puisqu'elle constitue elle-même un objet d'étude du plus grand intérêt, qui nous montre de façon inégalable comment fonctionne «l'esprit anglo » (cf. Wierzbicka 2006). Les nombreuses variétés régionales et sociales de la langue anglaise sont elles aussi des objets d'intérêt parce qu'elles reflètent également «l'esprit» de leurs locuteurs, et en révèlent le fonctionnement. Que l'on cherche à étudier les façons de penser « anglo », ou bien les façons de penser anglo-australiennes, ou encore les façons de penser des punks de langue anglaise, il faut toujours tenir compte de la perspective qu'impose sur l'objet d'étude la langue de l'enquête; et il en va de même quand on étudie des cultures liées à des langues autres que l'anglais.

Il y a douze ans, dans un article intitulé «Ethnopsychologie », Geoffrey White (1992 : 23) observa que «Certaines émotions dans des sociétés non anglophones (et non occidentales) sont communément appelées anger [fr. colère], comme si le sens de ce terme était à la fois transparent et culturellement neutre ». A leur tour, Kitayama et Markus (1994: 7) firent valoir, deux ans plus tard, qu'« en utilisant la notion anglaise de colère comme ancre et point de repère pour les comparaisons et les généralisations transculturelles, les théoriciens des émotions fondamentales risquent d'avoir promu une appréhension ethnocentrique des émotions ». Or, ce qui est vrai dans le cas de la « colère » et d'autres «émotions fondamentales » l'est également dans d'autres domaines sémantiques. Il suffit de penser à des domaines tels que les «traits de caractère », y inclus les soi-disant Big Five, les normes morales, les valeurs etc. Les remarques de White et de Kitayama et Markus s'appliquent en ethnophilosophie et en ethnosociologie aussi bien qu'en ethnopsychologie. Dans tous ces domaines, il faut se rappeler que l'anglais de l'enquête n'est ni transparent ni culturellement neutre. Cela ne veut pas dire que les comparaisons sont impossibles, mais plutôt qu'elles sont plus sûres si elles s'appuient sur ce noyau interne de l'anglais que l'anglais partage avec d'autres langues. En fait, plus elles s'y appuient, plus elles sont sûres.

Le plus souvent, le bilingue qui s'est établi dans le monde anglophone, que ce soit au moment de l'adolescence ou bien plus tard, ne manquera pas d'être frappé par le fait que certains des concepts les plus fondamentaux de l'anglais académique aussi bien que de l'anglais de tous les jours, et que les locuteurs natifs de l'anglais (y compris les chercheurs) ont tendance à considérer comme allant de soi, ne correspondent pas à des concepts de leur langue maternelle. Le témoignage de ces "émigrés linguistiques », 
qui confirme les résultats auxquels aboutissent les analyses sémantiques rigoureuses, mérite d'être pris en considération dans les études de la cognition, de la culture et de la nature humaines.

L'analyse sémantique, méthodologiquement saine, des différents vocabulaires du «soi » et de la vie intérieure nous offre des preuves « objectives » quant aux modes d'expérience cristallisés dans des langues différentes et transmis par ces langues d'une génération à l'autre. Par ailleurs, les témoignages des «autochtones culturels» - et avant tout de ceux qui sont à même de puiser dans leur propre vécu afin d'établir des comparaisons - nous offrent des preuves « subjectives ", non moins importantes que les preuves «objectives». Il en est de même dans le cas des normes et des postulats culturels différents reflétés dans des façons différentes de parler et d'interagir avec autrui, c'est-à-dire dans le cas de ce que mes collègues et moi appelons des «scénarios culturels » (cf. Wierzbicka 2003).

\section{Normes culturelles et universaux humains}

Alors que les monolingues sont souvent incapables d'apercevoir les lunettes qu'ils portent à longueur de journée, le bilingue - et particulièrement l'« émigré linguistique »- ne manquera jamais d'être frappé par le fait que chacune de ses langues lui montre une image différente du monde. Cela est vrai, non seulement par rapport à l'ethnopsychologie anglo contemporaine, dont la pierre angulaire est le mot anglais mind, mais aussi par rapport à l'ethno-éthique. À titre d'illustration, on me permettra d'entreprendre une étude du mot anglais fairness, qui joue un rôle de premier plan dans cette ethno-éthique, et que Pinker (2002) par exemple, dans sa défense de la «nature humaine », admet parmi les universaux humains.

L'ouvrage de Pinker inclut un appendice intitulé «La liste des universaux humains de Donald Brown ». La liste s'inspire essentiellement de l'important ouvrage du même titre que Brown a fait paraitre en 1991, et de son article de 1999 dans l'Encyclopédie MIT des sciences cognitives. A sa surprise, le lecteur non anglophone y trouvera non seulement des éléments tels que «one» 'un', "two» 'deux', "same» 'même', «good» 'bien' et «bad» 'mal', mais aussi «fairness» (sans parler de «wbite» 'blanc' et de «black» 'noir'). Ainsi que le montrent les recherches empiriques effectuées au cours des dernières décennies dans le cadre théorique MSN, les éléments UN, DEUX, MÊME, BIEN et MAL se retrouvent effectivement dans toutes les langues, avec une soixantaine d'autres (voir les Tables 1 et 2 ci-dessus). Laissant de côté «blanc» et "noir», déclarés universels dans l'ouvrage classique de Berlin et Kay (1969), mais dont on sait maintenant qu'ils ne le sont pas, on ne peut pas ne pas s'émerveiller devant l'inclusion de «fairness» dans la liste des concepts humains universaux de Brown. En réalité, le concept de «fairness» est une création unique de l'anglais moderne. S'il existe dans d'autres langues, c'est uniquement en tant qu'emprunt à l'anglais. C'est un concept qui s'est fait jour en anglais dans des circonstances historiques très particulières et qui est peu à peu devenu l'un des concepts clés de la culture anglo contemporaine, comme le montre, inter alia, la fréquence du mot fair en anglais moderne : on dénombre 101 occurrences par tranche d'un million de mots dans le corpus COBUiLD de l'anglais britannique parlé, alors que 
le nombre d'occurrences des mots just, reliable, truthful, thoughtful et considerate est de respectivement $33,9,3,1$ et 1 .

Essentiellement, le concept de «fairness» se fonde sur l'idée que «la coopération sociale est assurée par des règles et des procédures publiquement reconnues que les coopérants acceptent comme appropriées à la régulation de leur conduite» (Rawls 2001: 6). Le même auteur poursuit en disant: «Des conditions équitables de coopération sous-tendent l'idée de réciprocité ou de mutualité : tous ceux qui s'acquittent de leur tâche ainsi que le réclament les règles reconnues sont certains d'y gagner, et ce en fonction d'une norme publique et consensuelle » (ibid.). Rawls fait valoir que le concept de «fairness» a vu le jour dans l'Europe du dixseptième siècle, dans le contexte de la nouvelle philosophie politique du «contrat social ». A en juger d'après les données du OED (Oxford English Dictionary), le sens pertinent du mot fair a surgi en anglais au dix-septième siècle, et celui du mot unfair au dix-huitième.

On le voit: le concept de «fairness» n'est pas exactement universel. Pour l' "émigré linguistique », il s'agit souvent d'un concept qu'il est difficile d'acquérir et d'intégrer dans un système de valeurs préexistant. Mais il n'est peut-être pas surprenant que «fairness» a fini par se retrouver dans la liste des universaux humains de Brown (et par là dans l'appendice de l'ouvrage de Pinker 2002 sur la «nature humaine »): pour un grand nombre de locuteurs anglais il est simplement inconcevable que la «fairness» ne soit pas une préoccupation humaine universelle. C'est un excellent exemple de la façon dont la langue maternelle peut influencer les façons de penser et les postulats de ce qui est naturel et universel. C'est en même temps une bonne illustration des dangers d'une perspective monolingue dans les discussions de la «nature humaine » et de l' « esprit humain ».

En fait, un grand nombre de chercheurs qui s'expriment en anglais refusent simplement de croire que la «fairness» n'est pas un concept humain universel. Certains vont même jusqu'à se réclamer d'Aristote et de Piaget. Voici, à titre d'exemple, ce qu'écrit James Wilson (1993), dans son livre Le sens moral (qui est, si j’ai bien compris, à la base de l'inclusion de «fairness» dans la « liste des universaux humains» de Donald Brown) : « Le premier jugement d'ordre moral qu'énonce l'enfant est peut-être : 'That's not fair !' ['Ce n'est pas juste'] » (1993: 10). Remarquez bien: Wilson parle non pas de «l'enfant anglophone », mais simplement de «l'enfant »... Il continue en disant : « Au moment où [les enfants] entrent à l'école primaire, l'idée de 'fairness' a acquis un sens relativement bien défini : les gens ont droit à une part égale » (p. 11). D’après Wilson, ce sens correspond au concept aristotélicien de « justice distributive» :

Des preuves irréfutables de l'importance de la «fairness» comme principe régulateur de notre conduite nous viennent d'un vaste corps de recherches au sujet du comportement adulte. Dans ces études (et ici même), la «fairness» se définit plus ou moins comme Aristote définit la justice distributive : 'Ce qui est juste... est ce qui est proportionné' (Ethique de Nicomaque 1131b17) - c'est-à-dire que les objets de ce monde doivent être partagés en proportion de la fortune ou du mérite des gens.

Ce «vaste corps de recherches au sujet du comportement adulte» d'où nous viennent «des preuves irréfutables de l'importance de la 'fairness' comme principe 
régulateur de notre conduite » est indubitablement digne de foi - à condition que «notre conduite» soit interprétée comme «la conduite anglo» plutôt que «la conduite humaine». On conçoit mal que le concept de «fairness» puisse servir de principe régulateur à des locuteurs à qui ce concept est inconnu, c'est-à-dire aux locuteurs de la plupart, voire de la totalité, des langues autres que l'anglais, par exemple le polonais, l'allemand, le français, sans parler des langues aborigènes de l'Australie, auxquelles je reviendrai dans quelques instants. Je voudrais d'abord illustrer ce qui vient d'être dit en puisant dans ma propre expérience.

Autrefois, mes deux filles, grandissant en Australie, avaient l'habitude de me dire : «That's not fair!» (en polonais, "To nie fair!») - à quoi, exaspérée, je répondais que ce n'est pas un concept qui m'est familier. Mes filles, qui s'expriment tous les jours en anglais comme en polonais et qui recourent volontiers au mot anglais fair (mot qui correspond à un concept-clé de leur culture anglo-australienne prévalente), SAVAIENT de toute évidence qu'il n'y a pas de mot polonais correspondant à l'anglais fair, et elles glissaient dès lors ce mot dans leurs propos polonais. Moi, bilingue mais de culture avant tout polonaise, je SAVAIS que le concept de «fairness» m'était à la fois étranger et (du moins dans le cercle familial) offensif et offensant. L'une de mes filles ne cessait de me dire, avec une certaine animosité, «Tu détestes le mot fair». Elle avait raison : sa remarque était «fair»... (Un excellent exemple de choc culturel dans des familles bilingues et transculturelles.)

Passons au français. Il est trompeur de croire qu'en étudiant l'émergence des concepts « universels » de « juste » et de « justice », Piaget étudiait en fait l'émergence du concept de «fairness». Néanmoins, dans la version anglaise de son traité Le jugement moral de l'enfant (Piaget 1950), le mot français juste est traduit dans la plupart des contextes à l'aide du mot fair. Le lecteur de la traduction anglaise, inconscient des différences sémantiques entre le mot français juste et le mot anglais fair, aura peut-être l'impression que Piaget étudiait l'émergence du concept de «fairness», mais il n'en est rien. En effet, ayant demandé à des enfants (francophones, bien entendu) de lui fournir des exemples de ce qui n’est pas «juste», Piaget obtint à titre de réponse le mensonge, le vol, la casse, etc., aussi bien que les tricheries au jeu, ou bien la division d'un gâteau en tranches inégales. Le concept français correspondant au mot juste est manifestement différent du concept anglais correspondant au mot fair (même si la traductrice, Marjorie Gabain, dans ce contexte, traduit pas juste en disant not fair). En fait, le mot français juste invite des comparaisons non seulement avec l'anglais fair, mais aussi avec l'anglais just et right (p.ex. "it's not right to lie or steal», 'ce n'est pas juste de mentir ni de voler'). Le mot français traduit un concept assez différent de celui que traduit le mot fair, et n'a pas de connotation obligatoire de "réciprocité » ou de " coopération », pas plus que les mots anglais just et right (il n'est pas sans intérêt de noter qu'en anglais il est possible de décrire les administrateurs dans des institutions démocratiques comme étant fair. On dira ainsi "She is very fair», "She was a very fair chairperson / head of department»; mais il n'est pas tout à fait correct d'utiliser le mot juste dans ce contexte, et de dire *Elle est très juste, *Madame la Présidente est très juste). Le mot anglais fair et le mot français juste se chevauchent, mais ne se correspondent pas.

Il faut faire remarquer enfin qu'il est faux de prétendre que le concept anglais de «fairness» peut être adéquatement défini en termes de "parts égales », ou bien de 
Anna Wierzibicka

« justice distributive» à la façon d'Aristote. Le concept uniquement anglais de «fair play », par exemple, attesté à partir du dix-septième siècle, n'a rien à faire avec la "justice distributive», mais concerne «les règles du jeu» (cf. Richard Brome, 1640 : «Here's nothing but fair play, and all above board»; et de même Samuel Richardson, 1753 : «All is fair; all is above board» [cités par Stevenson 1957 : 914]). La non-universalité du concept anglo de «fairness» et le rapport qui existe entre ce concept et ce que Rawls (2001) appelle « la coopération sociale assurée par des règles publiquement reconnues » (c'est-à-dire bénéfiques à tous) se laissent illustrer à l'aide de l'histoire australienne que voici (où Ann est une aborigène et Janet une angloaustralienne) :

Il était samedi après-midi et le magasin était fermé. Ann, la mère de Jimmy, avait besoin d'aliments. Elle alla voir son amie Janet, la femme du marchand.

Ann entra dans la maison de Janet, et s'assit. Au bout d'un moment elle lui demanda : «Janet, tu m'ouvres le magasin? Ma petite fille est malade et je n'ai pas eu le temps d'acheter des aliments. »

Janet lui dit : «Désolée, Ann, mais c’est impossible. Tu sais bien qu’on dit à tout le monde qu'il est impossible d'acheter des aliments le samedi après-midi. Il faut acheter les aliments le samedi matin. Si j'ouvre pour toi, des tas d'autres gens voudront eux aussi acheter des choses. »

Janet remit à Ann un morceau de son pain à elle, mais Ann ne fut pas satisfaite. Janet était comme une «sœur» envers elle, et elles se rendaient souvent visite. Ann pensa que Janet n'avait pas agi comme une sœur. (Hargrave 1991 : 19)

Ainsi que le montre ce petit récit, la «fairness» n’est pas nécessairement une question de "parts égales» ou de «justice distributive». C'est plutôt (et approximativement) une question de règles (de «contrat social») identiques pour tout le monde, publiquement reconnues, et considérées bénéfiques à tous. Il est clair que ce concept est absent de la culture d'Ann, tout comme il n'y a aucun concept d'obligation parentale dans la culture de Janet. En outre, il n'y a pas de concept d'« équité » dans la culture de sa «sœur» aborigène. J'ai fait valoir ailleurs (Wierzbicka 2001b) qu'il y a certes un certain nombre de normes et de valeurs morales universelles, mais c'est une illusion anglocentrique de croire que la «fairness» ou l'« équité » en font partie.

Si nous voulons expliciter le concept de «fairness» à l'aide de concepts humains universels, un bon point de départ est l'observation qu'une phrase telle que «That's not fair » implique que quelqu'un n'était pas «fair» envers quelqu'un d'autre; et, de façon générale, agir envers quelqu'un d'une façon qui n'est pas «fair», c'est lui faire du mal. Une autre composante qu'on peut reconnaitre d'emblée est qu'il est question de choses que l'on fait avec une ou plusieurs autres personnes. «Faire des choses avec quelqu'un» est à interpréter d'une façon très large, et inclut toute forme d'interaction ou d'« affaires » avec autrui, pas forcément sur un pied d'égalité. Mais ce qui est tout à fait crucial, c'est qu'il faut que ces interactions se déroulent conformément à certaines règles.

Soit, par exemple, le cas d'un père décrit par un enfant unique comme étant «strict but fair ». S'il y avait d'autres enfants dans la famille, on pourrait s'attendre à ce 
que tous soient traités de la même façon, mais ce n'est pas l'interprétation appropriée dans le cas d'un enfant unique. "Fair», dans ce cas, implique-t-il que les mêmes règles sont observées par le père et l'enfant? Oui et non. Si l'une des règles est que «les devoirs passent avant la télévision", il est clair que seul l'enfant est directement concerné, et non pas le père : il n'y aura pas de télévision pour l'enfant tant que l'enfant n'aura pas fait ses devoirs. Cependant, si le père est «fair», la règle l'engage lui aussi : dès que l'enfant aura fait ses devoirs, il (ou elle) aura «le droit» de regarder la télévision, et le père ne pourra pas l'en empêcher.

L'impact de l'idée de « règle » sur le concept de «fairness» n'est pas limité à ce qui précède. Dans un certain sens, le concept de «fairness» implique qu'il y a des règles connues de tous et reconnues comme étant bénéfiques par tous ceux qui souhaitent «faire des choses » les uns avec les autres. Le lien entre «fairness» et « règles » est indicatif de l'existence d'un consensus implicite. Cette composante sémantique-là peut se formuler de la façon suivante : «tous ces gens doivent penser la même chose de certaines choses ». Considérées ensemble, les composantes d' «interaction» et de « consensus » nous donnent le scénario que voici :

[les gens pensent :]

si les gens veulent faire des choses avec certaines autres gens

ils doivent penser la même chose de certaines choses

En fonction de ce scénario, l'interaction - faire des choses ensemble - est volontaire ("si les gens veulent...»), mais certaines règles ("ils doivent...») sont de mise une fois que l'interaction est en cours. Le jeu est une instance appropriée de ce genre d'entreprise collective : la participation est volontaire mais, dès que le jeu est en train, les règles sont obligatoires (autrement, il n'y aurait pas de jeu). Il importe d'agir conformément aux règles, sans rechercher des avantages qui y soient contraires ; c'est un aspect essentiel du « fair play».

Le concept de «fairness» évoque la possibilité d'une tension entre les intentions d'un être humain et les conséquences négatives pour autrui. Un premier postulat est qu'il est bien qu'une personne puisse faire ce qu'elle veut faire - mais il y a un deuxième postulat, concomitant, à savoir qu'il faut prêter attention à la question de savoir si ce qu'on a l'intention de faire a des effets défavorables pour quelqu'un d'autre. Cela ne veut pas dire qu'il est nécessairement « unfair» qu'une personne veille à ses propres intérêts s'il peut y avoir des suites négatives pour autrui. Simplement, si je veux accomplir un acte qui porte préjudice à un autre, il y a des limites à ce que je peux faire de façon légitime. Certaines règles sont en vigueur qui limitent ma liberté d'agir au cas où mes actions seraient contraires aux intérêts d'autrui.

Toutes ces considérations nous permettent d'esquisser une définition des mots fair et unfair. La définition aura deux parties. La première partie, précédée de la parenthèse « les gens pensent», explicite les postulats qui sous-tendent le concept de «fairness ». La deuxième partie, précédée de la parenthèse « je dis », explicite le jugement du locuteur.

Cela (ce que la personne X veut faire) n'est pas «fair» $=$

[les gens pensent:]

si les gens veulent faire des choses avec certaines autres gens

ils doivent penser la même chose de certaines choses 
Anna Wierzicka

c'est bien s'ils pensent ainsi de certaines choses :

«si quelqu'un veut faire cela, ce n'est pas mal»

c'est bien s'ils pensent ainsi de certaines autres choses :

«si quelqu'un veut faire cela, c'est mal

parce que c'est mal pour quelqu'un d'autre

cette autre personne peut dire à cette personne: je ne veux pas que tu le fasses »

[je dis :]

je pense que $\mathrm{X}$ veut faire du mal

parce que $\mathrm{X}$ veut faire cet autre type de choses

je peux dire pourquoi je pense ainsi

je pense que d'autres gens peuvent penser la même chose

Nous n'avons pas cherché à spécifier quelles actions sont susceptibles d'être «unfair». Ce serait la mer à boire: trop de situations diverses se prêtent à des jugements de ce qui est «fair» et de ce qui ne l'est pas, de sorte que le recours à des formules simplistes telles que «la même chose pour tous» (dans le cas de «fair») et «pas la même chose pour tous» (dans le cas de "unfair») est inapproprié. En revanche, nous avons cherché à articuler les postulats qui sous-tendent ces jugements, et nous n'avons explicité le jugement lui-même (la deuxième partie de la formule) qu'en termes assez généraux.

Formulé de cette façon, le concept de «fairness » se laisse traduire dans toutes les langues, et devient accessible, sans distorsion, aux locuteurs des langues où ce concept n'existe pas. Il leur est en effet présenté du point de vue de l'initié, tout en étant parfaitement clair à des tiers. Notre explicitation réfute l'idée qu'on a affaire à un concept simple et universel (c'est-à-dire «câblé ») comme BIEN et MAL, MÊME, ou bien UN et DEUX, et illustre la complexité d'un concept dont les présupposés culturels sous-jacents peuvent être exprimés de la façon suivante :

- Dans l'intérêt de tous, il faut qu'il y ait des règles qui régissent l'interaction humaine, laquelle est dictée largement par des volontés individuelles.

- Il est impossible de formuler à l'avance la totalité de ces règles vraisemblablement parce que la vie est trop complexe et trop variée.

- Cependant, dans la plupart des situations, il est possible de faire appel à une règle globale que la majorité des gens sont disposés à juger " raisonnable » et d'application générale.

La « réglementation » de la vie à l'aide de règles d'interaction, les unes explicites, les autres implicites, n'est pas conçue comme un état de choses imposé sur une société de l'extérieur, mais comme quelque chose que tous les membres de la société s'engagent à accepter volontairement. Les règles sont d'ordre général, identiques pour tous (" démocratiques ») et volontaires (il y a un « contrat social »). L'approche adoptée est pragmatique et flexible (les règles ne sont pas nécessairement formulées à l'avance), et elle permet l'accomplissement libre des volontés de l'individu (c'est-à-dire qu'elle est « libérale »), tout en imposant certaines limites. 
Les présupposés culturels qui viennent d'être énumérés reflètent une philosophie politique et sociale spécifique, historiquement déterminée. Ceux qui s'en rendent compte ne trouveront guère étonnant que la plupart des langues du monde n'ont pas de mots correspondant aux mots anglais fair, fairness, et unfair (au sens pertinent, contemporain).

\section{Conclusion}

J'ai fait valoir que seule une «langue universelle » permet d'identifier de façon correcte les universaux humains, et qu'il en va de même dans le cas des différences transculturelles. J'ai fait valoir en outre qu'une «langue universelle » de ce type a d'ores et déjà été construite, sur la base d'universaux empiriques du langage. J'ai illustré les avantages concrets de l'approche MSN à l'aide d'exemples tirés de l'ethnopsychologie. Je me suis efforcée de relier les résultats d'une analyse sémantique «objective » à l'expérience «subjective » des bilingues, et particulièrement des «émigrés linguistiques ». Je me suis efforcée aussi de montrer comment des savoirs transculturels approfondis, basés sur des universaux conceptuels, c'est-à-dire sur des concepts humains simples et partagés, peuvent contribuer à la réalisation des objectifs pratiques de la communication et de l'éducation transculturelles.

Il y a douze ans, dans un article anglais intitulé "L'anthropologie et la psychologie : une relation qui n'est pas payée de retour », Theodore Schwartz (1992: 346) parla des «efforts herculéens » qui ont été fournis afin de "placer les diverses cultures de notre planète sous la loupe » et de mener à bien «l'énorme tâche de classer, d'évaluer et de comprendre les données accumulées». Il fit allusion (ibid.) à la « recherche d'une vérité qui arrive à petits pas » et lança pour terminer un appel aux psychologues: «Dans cet esprit, nous, anthropologues psychologiques, avons un message urgent pour nos collègues en psychologie, dont nous partageons l'objet d'étude : à savoir que ce que nous avons appris dans le domaine de la culture ne doit pas être ignoré - c'est une partie constitutive de la nature humaine aussi essentielle que le cerveau et le corps humains. »

Moi aussi, je crois que la vérité arrive à petits pas, et dans cet esprit je voudrais faire remarquer que ce que nous avons appris en matière d'universaux conceptuels ne doit pas être ignoré non plus; et que ces universaux sont eux aussi une partie constitutive essentielle de la nature humaine, comme le sont le cerveau, le corps, et la culture dans toute sa diversité, toute sa complexité et toute sa richesse. Ces universaux conceptuels ont été identifiés, non pas de façon spéculative, mais grâce à des enquêtes empiriques d'envergure, effectuées par de nombreux chercheurs, sur une longue période. Leur validité a été testée dans un grand nombre de langues typologiquement différentes, et dans un grand nombre de domaines sémantiques. Je ne crois pas qu'il soit prématuré de dire que la métalangue sémantique naturelle a fait ses preuves, et est un instrument analytique efficace dans la description des langues, dans l'exploration des cultures, dans la quête d'universaux humains, et dans la facilitation de l'entente transculturelle. J'ose croire que cet instrument continuera à nous être utile dans l'identification et la comparaison futures des schémas culturels et des postulats culturels qui nourrissent l'identité culturelle des gens, aussi bien que la diversité et la variabilité des cultures. 
Anna Wierzbicka

\section{RÉFÉRENCES BIBLIOGRAPHIQUES}

Bateson, G. \& MeAd, M., 1942, Balinese Character: A photographic analysis. New York, The New York Academy of Sciences.

BerLIn, B. \& KAY, P., 1969, Basic Color Terms : Their universality and evolution. Berkeley, University of California Press.

Besemeres, M., 1998, «Language and self in cross-cultural autobiography: Eva Hoffman's "Lost in Translation” ». Canadian Slavonic Papers 40(3-4) : 327-344.

Besemeres, M., 2002, Translating One's Self: Language and selfhood in crosscultural autobiography. Oxford, Peter Lang.

BESEMERES, M., à paraitre, «When one's point of view changes with one's language : Eva Hoffman's Lost in Translation». in J. Bartminski (réd.), Kategoria punktu widzenia. Lublin : Uniwersytet im. Marii Curie-Skódowskiej.

COBuild. The Collins COBUILD Bank of English. HarperCollins Publishers.

D'ANDrade, R. G., 1987, «A folk model of the mind», in D. Holland et N. Quinn (réd.), Cultural Models in Language and Thought. New York, Cambridge University Press : 112150.

Donald, M., 2001, A Mind So Rare: The evolution of human consciousness. New York, W. W. Norton \& Co.

ECO, U., 1994, La recherche de la langue parfaite dans la culture européenne. Traduit de l'italien par Jean-Paul Manganaro. Paris, Seuil.

Enfield, N. \& Wierzbicka, A. (réd.), 2002, Pragmatics and Cognition (numéro thématique consacré au corps dans la description des émotions).

GeErTZ, C., 1973, «Deep play: Notes on the Balinese cockfight», in C. Geertz, The Interpretation of Cultures. New York, Basic Books.

GODDARD, C., 1998, Semantic Analysis: A practical introduction. Oxford, Oxford University Press.

GODDARD, C., 2001, « Lexico-semantic universals : A critical overview ». Linguistic Typology 5(1) : $1-66$.

GodDARD, C. \& WierzBiCKA, A. (réd.), 1994, Semantic and Lexical Universals : Theory and empirical findings. Amsterdam, John Benjamins.

Goddard, C. \& WierzBickA, A. (réd.), 2002, Meaning and Universal Grammar: Theory and empirical findings. Amsterdam : John Benjamins.

Hargrave, S., 1991, Whitefella Culture. Darwin, Summer Institute of Linguistics.

HARKINS, J., 2001, «Talking about anger in Central Australia », in J. Harkins \& A. Wierzbicka (réd.), Emotions in Crosslinguistic Perspective. Berlin, Mouton de Gruyter : 197-215. 
HASADA, R., 2000, An Exploratory Study of Expression of Emotions in Japanese : Towards a semantic interpretation. Thèse de doctorat, Australian National University.

Hoffman, E., 1989, Lost in Translation: A Life in a New Language. New York, Dutton.

Hofstede, G., 1980, Culture's Consequences: International Differences in Work-Related V alues. London, Sage. Traduit et adapté par Daniel Bollinger (Bollinger, Daniel ; Hofstede, Geert. 1987. Les différences culturelles dans le management. Paris, Les Editions d'Organisation.)

HoogstRa, L. \& Miller, P. J., 1992, « Language as a tool in the socialization and apprehension of cultural meanings ", in T. Schwartz, G. M. White, C. A. Lutz (réd.), New Directions in Psychological Anthropology. Cambridge, Cambridge University Press : 83-101.

HunT, E. B. ; BANAjI, M. R., 1987, «The Whorfian hypothesis revisited : A cognitive science view of linguistic and cultural effects of thought», in J.W. Berry, S. H. Irvine, E. B. Hunt (réd.), Indigenous Cognition : Functioning in cultural context. Dordrecht, Nijhoff : 57-84.

JACKENDOFF, R., 1999, "The natural logic of rights and obligations », in R. Jackendoff, P. Bloom, K. Wynn (réd.), Language, Logic, and Concepts. Cambridge, MA, MIT Press : 6795.

Kagan, J. \& Snidman, N., 1991, "Temperamental Factors in Human Development», American Psychologist 46. 856-862.

KANE, R., 1994, Through the Moral Maze : Searching for absolute values in a pluralistic world. New York, Paragon House.

KeEsing, R., 1994, «Radical cultural difference : anthropology's myth ?», in M. Pütz (réd.), Language Contact and Language Conflict. Amsterdam, John Benjamins : 3-23.

Kecskes, I. \& PApP, T., 2000, Foreign Language and Mother Tongue. Hillsdale, NY : Erlbaum.

KitAyAMA, S. \& MARKuS, H. R., 1994, «Introduction », in S. Kitayama et H. R. Markus (réd.), Emotion and Culture: Empirical studies of mutual influence. Washington, DC, American Psychological Association : 1-18.

LuCY, J. A., 1997, "The linguistics of "color" », in C.L. Hardin \& Luisa Maffi (réd.), Colour Categories in Thought and Language. Cambridge, Cambridge University Press : 320-346.

LuTZ, C., 1988, Unnatural Emotions. Chicago, Chicago University Press.

Mathews, H. F. \& Moore, C. C., 2001, «Introduction », in Mathews \& Moore (réd.) : 1-18.

Mathews, H. F. \& Moore, C. C. (réd.), 2001, The Psychology of Cultural Experience. Cambridge, Cambridge University Press.

Munroe, R. L. \& Munroe, R. H., 2001, «Comparative approaches to psychological anthropology », in Mathews \& Moore (réd.) : 223-241.

PAvlenKo, A., 1998, «Second language learning by adults : Testimonies of bilingual writers ». Issues in Applied Linguistics 9 : 3-19.

PEeTERs, B. (réd.), 2006, Semantic Primes and Universal Grammar : Empirical evidence from the Romance languages. Amsterdam / Philadelphia, John Benjamins. Sous presse. 
Anna Wierzbicka

Pesmen, D., 2000, Russia and Soul: An Exploration. Ithaca, NY, Cornell University Press.

Piaget, J., 1932, Le jugement moral chez l'enfant. Paris, Presses Universitaires de France.

Piaget, J., 1950, The Moral Judgement of the Child. Traduit du français par Marjorie Gabain. London, Routledge \& Kegan Paul.

PINKER, S., 1999, L'instinct du langage. Paris, Odile Jacob. Traduction d'un original anglais.

PINKER, S., 2000, Comment fonctionne l'esprit. Paris, Odile Jacob. Traduction d'un original anglais.

PINKER, S., 2002, The Blank Slate: The modern denial of human nature. London, Allen Lane.

QuinN, N., 2002, «Cultural selves». The Self: From soul to brain (conférence de la NYAS, 26-28 septembre 2002), non publié.

RAWLS, J., 2001, Justice as Fairness : A restatement. Cambridge, MA, Belknap Press.

Russell, J. A., 1993, "Forced-choice response format in the study of facial expression?» Motivation and Emotion 17 : 41-51.

Russell, J. A., 1997, «Reading emotions from and into faces: Resurrecting a dimensionalcontextual perspective », in J. A. Russell et J. M. Fernández-Dols (réd.), The Psychology of Facial Expression. Cambridge, Cambridge University Press : 295-320.

SANTE, L., 1997, "Living in tongues », in I. Frazier, G. C. Ward, R. Atwan (réd.), The Best American Essays. New York, Houghton Mifflin : 121-133.

SChWARTZ, S. H., 1994, "Studying human values », in A.-M. Bouvy, F. J.R. van de Vijver, P. Boski, P. Schmitz (réd.), Journeys into Cross-Cultural Psychology. Amsterdam, Swets and Zeitlinger.

SCHWARTZ, T., 1992, "Anthropology and psychology: An unrequited relationship ", in Schwartz, White, Lutz (réd.) : 324-349.

Schwartz, T. \& White, G. M. \& LuTZ, C. A. (réd.), 1992, New Directions in Psychological Anthropology. Cambridge, Cambridge University Press.

SHORE, B., 1996, Culture in Mind: Cognition, culture, and the problem of meaning. New York, Oxford University Press.

ShWEder, R. A. \& Bourne, E. J., 1984, «Does the concept of the person vary crossculturally ?", in R. A. Shweder, R. A. LeVine (réd.), Culture Theory: Essays on mind, self, and emotion. Cambridge, Cambridge University Press : 158-199.

SLOBIN, D., 2000, «Verbalized events: A dynamic approach to linguistic relativity and determinism», in S. Niemeier, R. Dirven (réd.), Evidence for Linguistic Relativity. Amsterdam, John Benjamins : 107-138.

Stevenson, B., 1959, Stevenson's Book of Quotations, Classical and Modern. London, Cassell.

VAN BRAKEL, J., 1994, «Emotions : A cross-cultural perspective on forms of life », in W. M. Wentworth, J. Ryan (réd.), Social Perspectives on Emotion, t. II. Greenwich : JAI. 179-237.

White, G., 1992, « Ethnopsychology », in Schwartz, White, Lutz (réd.) : 21-46. 
WierzBickA, A., 1972, Semantic Primitives. Frankfurt, Athenäum.

WierzBickA, A., 1990, "The meaning of colour terms : Semantics, culture, and cognition». Cognitive Linguistics 1(1) : 99-150.

WierzBICKA, A., 1992, Semantics, Culture and Cognition: Universal buman concepts in culture-specific configurations. New York, Oxford University Press.

WierzBICKA, A., 1995, "Everyday conceptions of emotion: A semantic perspective ", in J. Russell, J.-M. Fernández-Dols, A.S.R. Manstead, J. C. Wellenkamp (réd.), Everyday Conceptions of Emotion: An introduction to the psychology, anthropology and linguistics of emotion. Dordrecht, Kluwer : 17-47.

WierzBickA, A., 1996, Semantics : Primes and universals. Oxford, Oxford University Press.

WIERZBICKA, A., 1999a, Emotions across Languages and Cultures : Diversity and universals. Cambridge, Cambridge University Press.

WIERZBICKA, A., 1999b, "Universals of colour" from a linguistic point of view ». Behavioral and Brain Sciences 22 : 723-733.

WierzBICKA, A., 2001, What Did Jesus Mean? Explaining the Sermon on the Mount and the Parables in simple and universal human concepts. New York, Oxford University Press.

WiERZBICKA, A., 2002, « Right and wrong : From philosophy to everyday discourse ». Discourse Studies 4(2). 225-252.

WiERZBICKA, A., 2003, « Russian cultural scripts ». Ethos 30(4) : 401-432.

WierzBICKA, A., 2006, The English Language : Meaning and culture. New York, Oxford University Press.

WiERZBICKA, A., A paraitre, «Universal human concepts as a tool for exploring bilingual lives». International Journal of Bilingualism (numéro thématique consacré aux approches cognitives du bi- et du multilinguisme, réd. Istvan Kecskes).

WiLSOn, J. Q., 1993, The Moral Sense. New York, Macmillan/The Free Press.

WittgensteIn, L., 1961, Investigations philosophiques. Traduit de l'anglais par Pierre Klossowski. Paris, Gallimard. [L'extrait reproduit p. 22 se trouve à la p. 50 de la version anglaise de 1953, et est cité ici d'après: De Koninck, Thomas. 2002. «Dire Dieu aujourd'hui ». Laval théologique et philosophique 58(3). 503-530. 508.]

Yoon, K.-J., 2003, Constructing a Korean Natural Semantic Metalanguage. Thèse de doctorat, Australian National University.

ZASORINA, L.N. (réd.), 1977, Častotnyj slovar' russkogo jaryyka. Moscow, Russkij Jazyk. 
